\section{O agente comunitário de saúde e a privacidade das informações dos usuários}

\author{
Community health agents and patients' privacy
}

\section{Abstract}

This is an exploratory study on views of various social players in the Brazilian Family Health Program, concerning the right to privacy in the relationship between users of the program and community health agents (CHA). The following healthcare professionals were interviewed: heads of basic healthcare units, physicians, nurses and community health agents, working at health units in the city of São Paulo, Brazil, in 2002. Healthcare professionals and managers agreed that limits should be placed on access by CHAs to certain user information, including diagnosis. The study showed that frequent contact between users and CHAs results in users' disclosure of their health conditions to CHAs prior to consulting other professionals in the healthcare team. This generates the following ethical issue: Is there any specific scope of confidentiality between the CHA and users over information that should not be disclosed to other team members?

Bioethics; Institutional Ethics; Privacy
Paulo Antonio de Carvalho Fortes 1 Simone Ribeiro Spinetti 1

\section{Introdução}

Dentre os direitos dos usuários que podem ser garantidos em um projeto de humanização dos serviços de saúde está o direito à privacidade das informações. Este é um princípio derivado da autonomia, e engloba a intimidade, a vida privada, a honra das pessoas, significando que são os próprios indivíduos que têm direito de decidir que sua informações pessoais sejam mantidas sob seu exclusivo controle, como têm direito de comunicar a quem, quando, onde e em que condições as informações pessoais devam ser reveladas 1,2 .

O Agente Comunitário de Saúde (ACS), integrante das equipes vinculadas ao Programa Saúde da Família (PSF), possui uma situação singular, uma vez que deve obrigatoriamente residir na área de atuação da equipe e exercer a função de elo de ligação entre a equipe e a comunidade, o que faz com que viva o cotidiano da comunidade com maior intensidade do que os outros membros da equipe de saúde. Por ter maior proximidade com o usuário, por habitar o mesmo bairro, e ainda, por adentrar freqüentemente o domicílio do usuário, é importante que se estabeleçam novas relações no tocante às informações pessoais sobre a saúde individual e familiar, garantindo a privacidade daqueles com quem o ACS se relaciona na comunidade.

Assim, tendo como marco a humanização dos serviços de saúde, nos propusemos a reali- 
zar um estudo de natureza exploratória, objetivando conhecer a visão (opiniões e expectativas) de diversos atores sociais envolvidos em unidades que atuam no PSF da cidade de São Paulo, Brasil, sobre o direito à privacidade nas relações entre os usuários e os agentes comunitários de saúde.

Neste trabalho priorizamos estudar unidades da cidade de São Paulo, pois a experiência neste município diferencia-se de experiências anteriores com PSF realizadas em regiões rurais ou em locais com características econômicas, sociais e culturais diversas desta grande metrópole.

\section{Procedimentos metodológicos}

Realizou-se pesquisa qualitativa, de caráter exploratório, com orientação analítico-descritiva. Pesquisa orientada pela ética descritiva, que é a investigação da conduta moral, utilizando-se de procedimentos e metodologias de cunho científico para estudar como as pessoas equacionam e agem, ou ainda como se comportam, em circunstâncias particulares que trazem problemas éticos 3 .

Utilizou-se amostragem não probabilística, tipo acidental, não tendo havido definição prévia do número de pesquisados, uma vez que objetivava-se atingir o ponto de saturação que refletisse as tendências prevalentes dos grupos pesquisados, segundo as orientações de Minayo 4 e Contrandiopoulos et al. 5 .

Optou-se, então, por pesquisar unidades de saúde de dois Distritos de Saúde (atualmente: Coordenadorias de Saúde) que estivessem em fase inicial de implementação do PSF. Foram escolhidos o Distrito do Santo Amaro (Unidade Básica do Jardim Niterói) e o Distrito de Saúde de Cidade Ademar (Unidade Básica do Jardim Guacuri).

Foram entrevistados: as Chefias das Unidades Básicas de Saúde com Equipes de Saúde da Família $(n=2)$, a totalidade de Médicos $(n=6)$ e Enfermeiros $(n=3)$ participantes das Equipes de Saúde da Família, e metade dos ACS ( $n=24)$.

As entrevistas se deram em agosto de 2002, período em que se iniciava a implementação do PSF nas unidades, após a capacitação inicial dos ACS. Foram submetidos a entrevistas semi-estruturadas, com as seguintes questões abertas: (1) Qual o papel a ser desempenhado pelos agentes comunitários de saúde?; (2) $O$ agente de saúde pode ou deve conhecer as pato- logias ou os problemas de saúde de todos os usuários com quem se relaciona? Deve haver alguma restrição?

Os agentes comunitários de saúde foram também pesquisados mediante entrevistas semi-estruturadas, com uma questão aberta: (1) Você deve e pode saber sobre as doenças ou problemas de saúde que têm os usuários com quem você lida?

Foi realizado pré-teste para adequação dos instrumentos de coleta de dados utilizado, aferição das dificuldades encontradas e capacitação dos pesquisadores envolvidos no projeto. As entrevistas foram realizadas pelo pesquisador auxiliado por duas alunas de Pós-graduação da Faculdade de Saúde Pública da Universidade de São Paulo (FSP-USP); os discursos dos pesquisados foram gravados e transcritos na íntegra.

A interpretação do material coletado seguiu os ensinamentos de Bardin 6 e Gil 7 , por meio da técnica de "análise de conteúdo", escolhida pela possibilidade de adequação às diversas condições (locus) de produção da palavra ocorrentes na pesquisa. Segundo as diretrizes e normas da Resolução 196/96, do Conselho Nacional de Saúde/Ministério da Saúde, que regulamenta a ética da pesquisa envolvendo seres humanos no Brasil, a cada um dos sujeitos da pesquisa foi demandado o consentimento expresso para participar no estudo. Todos os entrevistados foram mantidos sob anonimato, e os resultados apresentados sob forma de siglas seguidas por numeração, por exemplo: médicos = M1, M2, M3 etc.; enfermeiros = E1, E2, E3 etc.; gerentes de unidades = G1, G2; agentes comunitários de saúde = ACS1, ACS2, ACS3 etc. Aos dirigentes das instituições foi solicitada autorização prévia para a realização da pesquisa. A elas não será revelado nenhum dado isoladamente e tampouco a decisão individual de cada profissional participar ou não da pesquisa. O projeto de pesquisa foi submetido e aprovado pelo Comitê de Ética em Pesquisa da FSP-USP em 16 de outubro de 2001. A pesquisa foi financiada e aprovada em seu relatório final pela Fundação de Amparo à Pesquisa do Estado de São Paulo (FAPESP), processo no 2001/11031-7. 


\section{Resultados}

\section{Gerentes e profissionais de saúde}

A preocupação gerencial com a privacidade das informações dos usuários vis-à-vis do ACS foi assim revelada: "uma das questões que a gente tem discutido muito com os agentes é a questão da ética e do sigilo, e isto não é tão fácil... com a própria equipe médica até. Alguns têm algumas restrições em relação a isto e tem outros que não têm problema nenhum que a gente acha até que é mais complicado, né? O perigo é assim, é estar discutindo de uma forma muito aberta esta questão do diagnóstico e dos problemas" (G1).

Também é manifesta nas falas dos profissionais de saúde: "ele [o agente] não deve ter acesso à informação altamente confidencial. Deve ter capacidade de transmitir informações simples e gerais. Informações sobre higiene, informação sobre transmissão de doenças, sobre prevenção de maneira geral. Então, acho que o agente vai lá, recolhe uma informação que o paciente se voluntaria a dar" (M2).

"Existem alguns pacientes que não querem que outras pessoas fiquem sabendo, e eu acho que o direito da privacidade do paciente deve ser respeitado e o agente de saúde deve também ter um código de ética a ser seguido e eles também devem respeitar o sigilo" (M4).

Parece ter sido incorporada a noção de que o usuário deve conhecer os limites da atuação do agente e deve ser esclarecido sobre seu direito em revelar ao ACS suas informações pessoais: “(...) o paciente também tem que saber que ele não é obrigado a entrar em detalhes com o agente, ele pode chegar para o agente e falar "eu preciso de uma consulta, eu preciso falar com médico e não quero comentar este assunto" e isso precisa ser respeitado. Nós tivemos até um caso recente de uma paciente que tinha HIV e inicialmente não quis que a gente soubesse. Então, foi feito como sempre o pacto com o profissional de que esta informação não seria divulgada pra agente" (M2).

"Por outro lado, o paciente deve saber que como o agente de saúde vai contar as coisas pra gente, o problema da confidencialidade é assim, já existiu caso do paciente chegar e falar não conta pro médico isto... mas, é uma coisa complicada, porque o agente de saúde, na verdade, tem a obrigação de repassar essa informação" (M2).

A troca de informações entre os elementos da equipe de saúde é entendida como necessária, mas devendo ser limitada àquelas informações que cada profissional precisa para realizar suas atividades em benefício, para o cuidado do paciente. Esta informação privativa seria mediada pelos profissionais de saúde que estabeleceriam, caso a caso, seus limites: “assim, diagnosticado, também cabe à enfermeira e ao médico ir triando de forma que tenha informações que vão ser altamente sigilosas. Agora, precisa se ter cuidado, muito cuidado" (E2).

"Você vai visitar fulano de tal, então confere medicação, vê se ele tá tomando, vê se ele tá fazendo o controle da pressão, este tipo de coisa" (M2).

“(...) Agora a patologia em si, acho não há necessidade do agente estar sabendo. Acho assim, se for alguma coisa que ele possa contribuir, por exemplo, ele diz que é hipertenso e é hipertenso, então ele pode contribuir" (G2).

Entende-se que a organização do trabalho do PSF facilita que as informações, mesmo que sigilosas, possam ser disseminadas, por isso, a capacitação e a educação continuada do ACS devem estar presentes nas atividades cotidianas da equipe: "agora tem coisas que são muito difíceis de esconder... ainda que a gente não fale e não conte para a agente, o agente com o tempo começa a juntar e ver e deduzir coisas, tanto corretamente quanto incorretamente, então, óbvio, é preciso de um treinamento constante" (M2).

Para gerentes, médicos e enfermeiros, o fato do ACS não ser um profissional ou técnico regulamentado, submetido ao controle de órgãos reguladores profissionais, traz incertezas e preocupações quanto à observação do princípio ético da privacidade das informações: "a gente tem assim, reforçado, por ter uma questão que assim, o agente comunitário tem a formação diferente do auxiliar de enfermagem que tem a formação durante 3 anos (...) é, sei lá (...), e técnico de enfermagem depois de mais um ano de formação, além do auxiliar, então é muito inicial a discussão" (G1).

"Não está submetido a uma ética profissional como os demais profissionais" (M2).

Cabe ainda considerar que esse novo modelo assistencial traz uma importante questão, outrora não existente, referente à privacidade do próprio agente comunitário, ou seja, como preservá-la enquanto morador de uma determinada comunidade, já que, se está nessa função em certo momento, isto não significa que nela continuará por tempo indeterminado, mas continuará sendo morador e vizinho, ainda que deixe a função e ACS: "você abrir estes diagnósticos é (....) com uma população que reside no local em contato então isto me preocupa" (G1).

“(...) O vizinho tem uma doença infectocontagiosa e ele é o melhor amigo, ele é o melhor amigo da pessoa. Então fica complicado para se trabalhar esta questão, até pra quem tem nível sócio-cultural e econômico mais alto" (E2). 
De acordo com as falas de gerentes e médicos pesquisados, o prontuário não deve ser aberto ao ACS, pois conteria fatos privativos, revelados somente para a relação profissional-usuário. A importância da guarda e a manutenção do prontuário deve-se a que possa resultar em danos para o paciente durante o acompanhamento no serviço ou mesmo posteriormente: "agora minha grande preocupação é que eu acho assim, dependendo do problema que o paciente tem, tem toda a questão do sigilo de prontuário, até que ponto a pessoa quer que outras pessoas saibam o que ela tem" (G2).

“Nós aqui não damos acesso de prontuário pros agentes de saúde. Eles entram na sala, puxam o prontuário e entregam na mão, mas abrir prontuário eles não estão autorizados" (M2).

\section{Agentes Comunitários de Saúde}

As respostas dos entrevistados parecem evidenciar que os ACS pesquisados compreendem, de forma clara, a necessidade da preservação do sigilo das informações que recebem: "o agente não vai falar nada, vai informar a Sra. que deve procurar a Unidade de Saúde onde fez o exame para pegar o resultado da mão do médico" A gente não pode falar nada, porque é fora de ética, não(...)" (ACS3).

“(...) E ele disse que gostaria que ninguém ficasse sabendo. Informei que independente da gente ser vizinho de jeito nenhum alguém ficaria sabendo, porque somos profissionais; com isso adquirem muita confiança" (ACS12).

"A gente acaba invadindo (a casa do usuário), fazendo parte da vida deles. Agora, se saio contando pra todo mundo, nunca mais vai confiar em mim, porque tem sempre alguém que confia em alguém e a turma vai passando" (ACS14).

Todavia, pode-se constatar que o contato freqüente com os usuários faz com que estes, muitas vezes, passem a revelar seus segredos ao ACS, abrindo mão de parte de sua privacidade quanto às doenças ou agravos de saúde que possuem, em virtude de considerarem que o ACS possa, com isso, facilitar seu acesso ao serviço de saúde: "parece incrível. Eles têm esse costume. Eles acham que a gente sabe tudo, mas não é verdade, porque a gente está há pouco tempo no programa. Eles acham assim, deixa eu falar que estou com problema sério no estômago que assim ela agiliza, me ajuda" (ACS1).

"Porque também a gente é agente de saúde e praticamente nasceu aqui, por exemplo, vim para cá com 3 anos e estou com 40. Vi crianças, vi pai da minha amiga morrer, então eles falam as coisas para mim, falam o que eles têm, falam seus medos e inseguranças, e partir disso é o trabalho da gente (...)" (ACS23).

Constatou-se existir preocupação com o princípio ético da privacidade e a necessidade da manutenção do sigilo profissional, tendo sido enfocado o princípio aos ACS das duas unidades durante o período da capacitação introdutória ao PSF, reforçando-se a liberdade do usuário para a realização das atividades propostas pelo PSF: “muitas vezes tem uma resistência formal até da própria matrícula da própria inscrição dessa família. Por que será que isso né... é se a pessoa tem resistência Você não vai forçar, né? ... E você vai ficar à disposição da pessoa. Só que você vai continuar sendo agente comunitário da rua, né?... do local da área que você está restrito, então avaliar um pouco por que será que a pessoa tem tanta restrição né? Então, às vezes, ela tem problemas mais sérios que ela não quer abrir, ou mesmo nem problemas de saúde, mas de relacionamento, e isto é uma coisa que tem que ser avaliada" (ACS14).

Foi marcante nos discursos dos ACS a utilização do termo ética, relacionando-o com a questão da privacidade das informações dos usuários: "muitos falam pra nós, que é uma ética que a gente aprendeu aqui que jamais a gente vai sair falando para o vizinho, para outro, não" (ACS2).

"Porque tem a Ética, a gente foi treinado assim, não pode falar para ninguém nenhum caso para marido, filhos, é restrito, só para a enfermeira" (ACS4).

"A gente não pode falar nada, porque é fora de ética, não(...)" (ACS3).

"Mas aí vem a ética, jamais. O que é discutido aqui, fica aqui e pronto, (...), então não, aí entra a ética, o que você sabe, fica pra você ou discute com sua equipe e só" (ACS9).

\section{Considerações}

Do direito do usuário à privacidade deriva o dever da manutenção do segredo por todos elementos da equipe, lembrando que são sigilosas não somente as informações reveladas confidencialmente, mas são todas aquelas que a equipe de saúde descobre no exercício de sua atividade, mesmo havendo desconhecimento do usuário. Assim, o dever de manter o segredo das informações constitui-se em obrigação ética dos profissionais, dos técnicos, dos auxiliares, do corpo técnico e administrativo e dos ACS 8.

Tendo sido recém-incorporado à equipe de saúde, as competências e responsabilidades do ACS têm sido estudadas e refletidas em diversos estudos, com preocupação para diferenciar 
a inserção institucional da inserção comunitária e sua diferenciação com as competências dos profissionais da equipe de enfermagem, que ainda não se encontram totalmente delimitadas 9,10,11.

Em nosso estudo, as falas dos entrevistados - gerentes e profissionais de saúde - mostraram fortes preocupações e ainda dúvidas quanto às relações do ACS com o direito dos usuários à privacidade das informações. Parece ser consensual entre profissionais e gerentes das equipes estudadas que limites devam ser estabelecidos para o ACS com relação ao acesso a determinadas informações pessoais dos usuários, como as que se referem ao diagnóstico de doenças, sobretudo as que podem trazer algum grau de estigmatização e/ou discriminação negativa para os usuários, como HIV/AIDS e transtornos mentais. Também, não devendo ser priorizado o conhecimento de estados patológicos, dos quais devem se ocupar os profissionais de saúde.

Ainda nos parece possível afirmar que nas duas unidades de saúde pesquisadas os ACS incorporaram a necessidade de garantir a privacidade das informações dos usuários com quem se relacionam.

A pesquisa mostra que o freqüente contato dos usuários com o ACS resulta em que os primeiros costumam revelar aspectos de suas condições de saúde para o agente, muitas vezes, antes mesmo do que aos outros integrantes da equipe de saúde, e isto pode gerar um dilema ético para os ACS. Desse modo, cabe questionar se todas as informações que recebem dos usuários, em confiança, devem ser repassadas aos outros elementos da equipe de saúde. Haveria uma esfera própria de confidencialidade entre o ACS e os usuários, com informações que não deveriam ser divulgadas aos outros membros da equipe de saúde?

Como relata uma entrevistada de Santos 9 , os ACS passam a ser portadores de segredos que podem resultar em riscos à própria vida, pois dizem respeito, muitas vezes, a atos ilícitos ou moralmente reprováveis. E, se os outros profissionais da equipe, fim de expediente, retornam a suas residências, na maioria, distantes dos locais de trabalho, os ACS continuam no local onde vivem e trabalham. O ACS convive, em várias regiões, com a violência organizada - gangues e narcotráfico. Verificou-se, entretanto, o cuidado que têm os ACS no envolvimento em casos desta natureza, dado que, como é parte de sua realidade nesta grande metrópole, vivem ao lado de pessoas que podem ter condutas consideradas como ilícitas: "eu sei, mas ele pode ter levado um tiro de policial, né? No caso assim, mais daí eu não poderia interferir, no caso se ele tá ferido por bala, ele vai precisar de uma assistência mais de perto. Daí eu estaria comunicando à unidade para ele ter uma assistência em saúde, tá? Agora, em relação ao BO alguma coisa assim, eu não poderia estar interferindo, tá bom?" (ACS17).

Finalmente, cabe salientar que a presença do ACS como elemento da equipe de saúde da família traz contribuição fundamental nas relações com os usuários do sistema público de saúde, visto que, conforme os dizeres de um dos agentes: "o usuário é muito, muito doente, não é de patologia nenhuma, é de amizade, compreensão de carinho de dar risadas sabe... então, a partir do momento que você fica mais amigo da população. Então eles vão ficando bons, sabe" (ACS4). 


\section{Resumo}

Estudo de natureza exploratória que objetivou conhecer a visão dos diversos atores sociais do Programa Saúde da Família sobre o direito à privacidade nas relações entre os usuários e os agentes comunitários de saúde. Entrevistados: Chefias das Unidades Básicas de Saúde, Médicos, Enfermeiros e Agentes Comunitários de Saúde (ACS), em 2002, de unidades de saúde da cidade de São Paulo, Brasil. Os profissionais e chefias entendem que devam ser estabelecidos limites para o ACS com relação ao acesso a determinadas informações dos usuários, como as que se referem ao diagnóstico de doenças. A pesquisa mostra que o freqüente contato dos usuários com o ACS resulta na revelação de aspectos de suas condições de saúde antes de fazêla a outros elementos da equipe de saúde. Isto gera uma questão ética a ser ainda debatida: há uma esfera própria de confidencialidade entre o ACS e os usuários, com informações que não deveriam ser divulgadas ao restante da equipe?

Bioética; Ética Institucional; Privacidade

\section{Colaboradores}

Os dois autores foram responsáveis pela escolha temática, planejamento e operacionaliazação da pesquisa, incluindo as entrevistas efetuadas e elaboração do texto final apresentado.

\section{Referências}

1. Sacardo DP. Expectativa de privacidade segundo pessoas hospitalizadas e não hospitalizadas: uma abordagem bioética [Dissertação de Mestrado]. São Paulo: Faculdade de Saúde Pública, Universidade de São Paulo; 2001.

2. Sacardo DP, Fortes PAC. Desafios para a preservação da privacidade no contexto da saúde. Bioética 2000; 8:307-22.

3. Zoboli ELCP. Bioética e atenção básica: um estudo de ética descritiva com enfermeiros e médicos do Programa de Saúde da Família [Tese de Doutorado]. São Paulo: Faculdade de Saúde Pública, Universidade de São Paulo; 2003.

4. Minayo MCS. O desafio do conhecimento. Pesquisa qualitativa em saúde. São Paulo: Editora Hucitec/Rio de Janeiro: ABRASCO; 1994.

5. Contandriopoulos AP, Champagne F, Potvin L, Denis JL, Boyle P. Saber preparar uma pesquisa. São Paulo: Editora Hucitec/Rio de Janeiro: ABRASCO; 1994.
6. Bardin L. Análise de conteúdo. Lisboa: Edições 70; 1994.

7. Gil AC. Como elaborar projetos de pesquisa. São Paulo: Editora Atlas; 1994.

8. Fortes PAC. Ética e saúde. São Paulo: Editora Pedagógica Universitária; 1998.

9. Santos RMB. Projeto Qualidade Integral em Saúde (QUALIS): relato de uma experiência (abril de 1996 a junho de 1999) [Dissertação de Mestrado]. São Paulo: Faculdade de Saúde Pública, Universidade de São Paulo; 2001.

10. Silva JA. O agente comunitário de saúde do Projeto Qualis: agente institucional ou agente comunitário? [Tese de Doutorado]. São Paulo: Faculdade de Saúde Pública, Universidade de São Paulo; 2001.

11. Sousa MF. Agentes comunitários de saúde: choque de povo. São Paulo: Editora Hucitec; 2001.

Recebido em 04/Fev/2004

Versão final reapresentada em 30/Abr/2004 Aprovado em 10/Mai/2004 